\title{
Editorial
}

\section{Clinical postcards}

\author{
Sergio Della Sala ${ }^{a, *}$, Roberto Cubelli $^{b}$ and Robert D. McIntosh ${ }^{a}$ \\ a Human Cognitive Neuroscience, Psychology, University of Edinburgh, UK \\ b Department of Psychology and Cognitive Sciences, Universita' di Trento, Italy
}

We are launching an ultra-brief format for Cortex, as an initiative to re-unite the efforts of clinicians and researchers to advance knowledge in Neuropsychology. Under the label, 'Clinical Postcards', clinicians and researchers are encouraged to submit short communications from the frontline of daily practice. These may be informal insights or impressions held about some patient group or condition, descriptions of symptoms rarely or never reported, interesting observations or incipient theories. The ideas may be tentative and exploratory rather than fleshed out with experimental data and theoretically clad, but they should not be widely discussed in the recent research literature. With this novel format, we aim in some small way to facilitate fruitful dialogue between clinical practice and academic neuropsychology.

The remit of Cortex, since its inception, has been the study of cognition and, in particular, the relationship between mind and brain. The careful observation of brain-damaged patients was, for many years, the dominant method to investigate this relationship, whilst the study of the functional organization of the mind owes considerably to the so called "diagram makers" (see e.g., Jacyna, 2004a, 2004b, 2005), operating mainly in Germany and France in the last decades of the 19th century, who developed models of cognition based on detailed observations of single cases. The nascent discipline of Cognitive Neuropsychology was thus built upon clinicalobservations of striking single-cases, from Leborgne to HM. The delineation of patterns of association and dissociation, initially rooted in the medical syndrome approach, developed into detailed functional analyses based on theoretical cognitive models. Notwithstanding the wealth of techniques available to contemporary Cognitive Neuroscience, the study of brain-damaged patients continues to offer critical and unique insights into the functional architecture of the mind, and its neural bases.
The translation from clinical observation to scientific theory, however, requires strong links between clinical practice and academic research. These links are potentially now weakened by several factors, including the prepotent advent of neuroimaging investigation with neurologically intact participants, an increased difficulty in securing funding for exploratory studies, the fact that in several countries specialist neuropsychologists are not a common part of the clinical team (in earlier times the behavioural neurologists were partly covering this need). Moreover, in several academic and clinical realities, ever-more glacial and bureaucratic ethics procedures severely inhibit the more reactive and exploratory modes of neuropsychological research, where observations could directly inspire behavioural experiments in a rapid loop (see Baron, in press). With the Clinical Postcards format, we aim to reiterate the centrality of clinical observation to Neuropsychology, our view being that intriguing clinical observations can often be the spur for novel and informative experimental work.

Clinical insights offer the possibility of detecting unexpected symptoms or unusual patterns of spared and impaired abilities, and of anticipating observations to further investigate experimentally. Consider the myriad insights of Elizabeth Warrington (see Fig. 1). Working in clinical settings, Warrington and co-workers foresaw many phenomena that became theoretically relevant, from the selective impairment of semantic memory (1975), to concrete word dyslexia (1981) and neglect dysgraphia (1983), to name a few. Clinical observations may quite often beat odds with the reigning academic consensus, forcing a re-evaluation. Two examples from the neglect syndrome may serve this point. Clinical data unexpectedly suggested that Visual neglect without visual extinction is a frequent pattern (e.g., Vallar et al., 2002), in contrast to an accepted view in which extinction was self-evidently a milder

\footnotetext{
* Corresponding author.

E-mail address: sergio@ed.ac.uk (S. Della Sala). http://dx.doi.org/10.1016/j.cortex.2014.12.003

0010-9452/@ 2015 Elsevier Ltd. All rights reserved.
} 


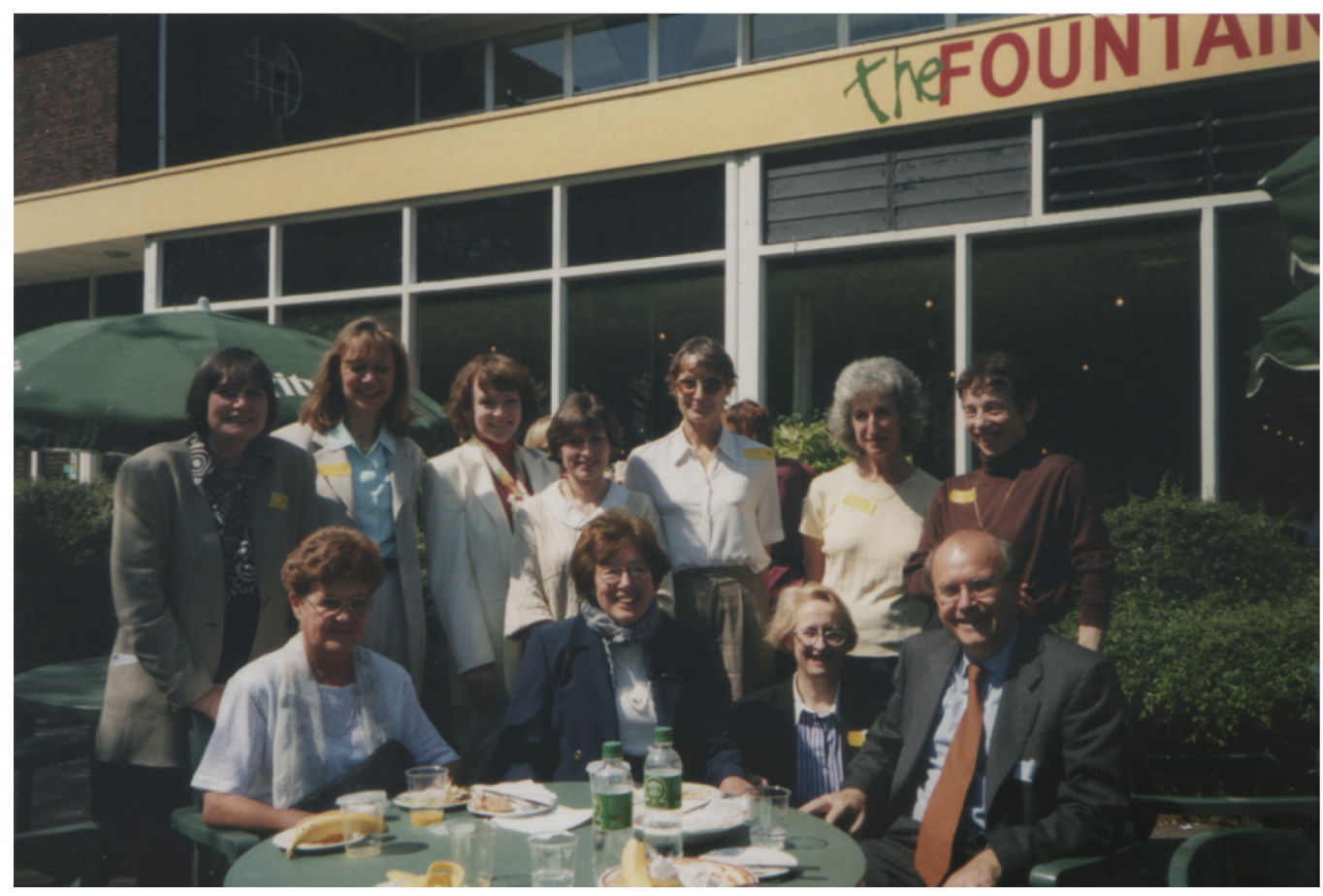

Fig. 1 - Elizabeth Warrington with some of her collaborators. Back row: Merle James, Lisa Cipolotti, Roz McCarthy, Angela Costello, Doreen Baxter, Pat McKenna, Helen Brittan; front row: Marianne Jackson, Elizabeth Warrington, Francis Clegg, Tim Shallice. Elizabeth is endorsing the Clinical Postcards initiative, she stated, "I feel very strongly that good cognitive neuropsychological studies should and do stem from clinical observation and it takes an awful lot of time to build up a base of what is usual and what is exceptional" (personal communication, 19/11/2014).

manifestation of neglect. In fact, neglect without extinction had been frequently observed by clinicians, and reported anecdotally, yet was rarely discussed in the research literature until experimentally tackled (Cocchini, Cubelli, Della Sala, \& Beschin, 1999). Similarly, Fig. 2, taken from Luria's "Higher Cortical Functions in Man" (1966) shows an early, interesting, clinical observation of drawing performance in a patient with neglect (described therein as "unilateral spatial agnosia"), not

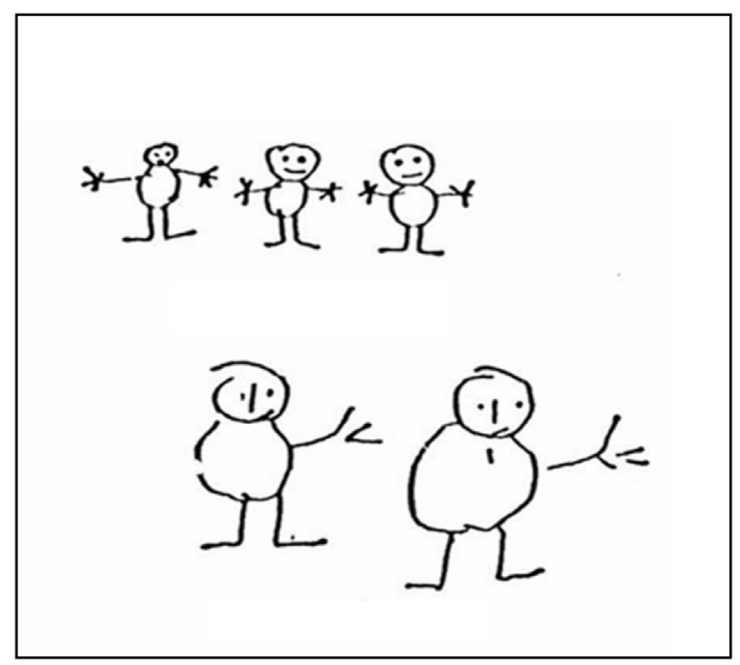

Fig. 2 - Illustration redrawn from Lurija's "Higher Cortical Functions in Man" (1966). framed by a theoretical construct available at the time. The figure in fact comes from clinical observations of the ' 50 s, but object-based manifestations (e.g., Gainotti, Messerli, \& Tissot, 1972; Walker, 1995) and productive phenomena in neglect (e.g., Rusconi, Maravita, Bottini, \& Vallar, 2002) were formally studied only much later. This research effort has now fed back into clinical practice, in that a recent standardised cancellation test of neglect (the 'Apples Test' from the Birmingham Cognitive Screen: Humphreys, Bickerton, Samson, \& Riddoch, 2012) was designed explicitly to discriminate space-based and object-based manifestations, a distinction that may have prognostic significance for functional outcome (Bickerton, Samson, Williamson, \& Humphreys, 2011).

Henri Hecaen maintained that "Sprung from clinical observations, Neuropsychology does not recant it: each observation of a patient potentially constitutes a privileged object of study, insofar as the specificity of the impairments noted by the clinicians could inform novel interpretations" (1972, p. 4).Clinical examinations may present phenomena ripe for experimental investigation, but clinicians themselves may not have the time or the means to extend or deepen the neuropsychological assessment or to conduct formal experiments. We are therefore lamenting the disconnection that often exists between neuropsychological researchers and clinicians (neurologists or psychologists) who actually meet and examine large numbers of patients. Several of us might remember occasions where a chance observation, or something that a patient or clinical colleague has said, have led us to approach a question in a new way, or launch a test of an 
idea that would not otherwise have emerged. Within this spirit, we are launching the Cortex initiative Clinical Postcards.

What we seek are clinical insights, of a scope that might be conveyed on a (large) postcard. This might be a snippet of $\sim 500$ words (though we won't be formal about length) recounting an unusual observation of possible significance, or a survey of broader scope, though not necessarily much greater length, discussing a rarely described clinical condition, symptom or assessment procedure. The observations and ideas will be intriguing, informative or instructive enough to merit sharing, yet too scant or informal to support a proper experimental paper. In proposing this novel format, we freely confess that we do not know how viable it could be; we are seeking seeds of inspiration, in the hope that a few flowers may grow.

In this issue we publish two Clinical Postcards to set the scene and offer examples of formats, which range from short, interesting observations on patients' behaviour (e.g., Stone and Carson) to more formally reported observed patterns of spared and impaired cognitive functions (e.g., McCarthy and Pengas). We hope that these will be of interest to clinical and academic readers alike, and that they may encourage further dialogue and cross-fertilisation, as well as further Clinical Postcards.

Please submit any observations that you have which may fit this format, and we at Cortex will be delighted to consider them for publication under the banner of Discussion Forum. Should you wish to discuss your ideas on possible Clinical Postcards before submitting them formally, please send to us a pre-submission enquiry, we will take matters from there.

\section{R E F E R E N C E S}

Baron, J. (2015). Some fallacies of human-subjects protection, and some solutions. Cortex (in press).
Baxter, D. M., \& Warrington, E. K. (1983). Neglect dysgraphia. Journal of Neurology, Neurosurgery and Psychiatry, 46(12), 1073-1078.

Bickerton, W. L., Samson, D., Williamson, J., \& Humphreys, G. W. (2011). Separating forms of neglect using the Apples Test: validation and functional prediction in chronic and acute stroke. Neuropsychology, 25(5), 567-580.

Cocchini, G., Cubelli, R., Della Sala, S., \& Beschin, N. (1999). Neglect without extinction. Cortex, 35(3), 285-313.

Gainotti, G., Messerli, P., \& Tissot, R. (1972). Qualitative analysis of unilateral spatial neglect in relation to the laterality of cerebral lesions. Journal of Neurology, Neurosurgery and Psychiatry, 35, 545-550.

Hecaen, H. (1972). Introduction à la neuropsychologie. Paris: Libraire Larousse, Paris.

Humphreys, G. W., Bickerton, W.-L., Samson, D., \& Riddoch, M. (2012). Birmingham cognitive screen (BCoS). Hove: Psychology Press.

Jacyna, S. (2004a). Lichtheim's "House". Cortex, 40(3), 413-414.

Jacyna, S. (2004b). Bastian's four centres. Cortex, 40(1), 7-8.

Jacyna, S. (2005). Jean-Martin Charcot's mechanisms of language. Cortex, 41(1), 1-2.

Lurija, A. R. (1966). Higher cortical functions in man (Originally published by Moscow University Press, 1962). New York: Basic Books.

Rusconi, M. L., Maravita, A., Bottini, G., \& Vallar, G. (2002). Is the intact side really intact? Perseverative responses in patients with unilateral neglect: a productive manifestation. Neuropsychologia, 40(6), 594-604.

Vallar, G., Rusconi, M. L., Bignamini, L., Geminiani, G., \& Perani, D. (2002). Anatomical correlates of visual and tactile extinction in humans: a clinical CT scan study. Journal of Neurology, Neurosurgery and Psychiatry, 57(4), 464-470.

Walker, R. (1995). Spatial and object-based neglect. Neurocase, 1, 371-383.

Warrington, E. K. (1975). The selective impairment of semantic memory. Quarterly Journal of Experimental Psychology, 27, 635-657.

Warrington, E. K. (1981). Concrete word dyslexia. British Journal of Psychology, 72(2), 175-196. 